\title{
Informality and accessibility to jobs by public transit: Evidence from the São Paulo Metropolitan Region
}

\author{
Geneviève Boisjoly \\ School of Urban Planning \\ McGill University* \\ E-mail: genevieve.boisjoly@mail.mcgill.ca \\ Ana Isabel Moreno-Monroy \\ Applied Economics Department \\ Autonomous University of Barcelona \\ E-mail: anaisabel.moreno@uab.com \\ Ahmed El-Geneidy \\ School of Urban Planning \\ McGill University* \\ E-mail: ahmed.elgeneidy@mcgill.ca \\ * McGill University \\ Suite 400, 815 Sherbrooke St. W. \\ Montréal, Québec, H3A 2K6 \\ Canada \\ Tel.: 514-398-8741 \\ Fax: 514-398-8376
}

For Citation please use: Boisjoly, G., Moreno-Monroy, A., \& El-Geneidy, A. (2017). Informality and accessibility to jobs by public transit: Evidence from the São Paulo Metropolitan Region. Transport Geography, 64, 89-96. 


\begin{abstract}
Access to opportunities through public transport can have different impacts on individual's life especially in developing countries where opportunities are limited, job informality rates are high, and socioeconomic characteristics gaps are big. The aim of this paper is to explore the relationship between job informality and accessibility to employment by public transport in São Paulo Metropolitan Region (SPMR), Brazil. To do so, we calculate a cumulative-opportunity measure of accessibility to jobs for 633 areas within the SPMR. We use a multilevel mixed-effects logistic regression model to estimate the effect of job accessibility on the likelihood of being informally employed, controlling for individual and other area characteristics. To account for informal sector heterogeneity, two regression models are generated: one for the workers earning below minimum wage and one for the workers earning above minimum wage. The results show that accessibility to jobs is unevenly distributed across the region, largely concentrated in the core of the region, and especially in the high-income areas. The regression results show that for workers earning less than the minimum wage, a higher level of accessibility to jobs by public transport is associated with a lower likelihood of being a worker in the informal job sector. For informal workers earning more than the minimum wage, car ownership seem to be more relevant than transit accessibility in determining the likelihood of being part of the informal job sector. In light of these findings, increasing accessibility by public transport through either expanding transit services to areas with high informality rates to have a better access to formal jobs or supporting the decentralization of formal jobs may be a way to achieve reductions in informality rates, especially among those earning less than the minimum wage.
\end{abstract}




\section{Introduction}

In emerging and developing economies, access to opportunities is one of the main reasons why people move to cities. Areas with good access to opportunities in cities are generally more expensive as people are willing to pay more for housing located in areas with better access to opportunities and especially jobs, which makes it difficult and costly for a significant part of the lower-income population to reside in these areas. Also in many cases public transport provision, which can be a good tool to provide accessibility to jobs for low-income groups, tend to be biased against the less affluent areas while jobs are concentrated in central areas and areas with higher land values (Camara and Banister, 1993). The centralization of jobs and the lack of public transit service serving low income areas to reach these jobs are the major obstacles that such vulnerable groups face when trying to reach job opportunities in a region, which may result in more prevalence of informal employment among this group. Informal employment is generally characterized by contractual relations that do not comply with national labor laws. Informal workers often face more risky conditions than formal workers, they may receive a lower compensation, cannot be part of a pension scheme, have no record of their job experience, and are not eligible for subsidies and leaves (including transport subsidies). For the economy at large, the existence of informal employment also implies losses in terms of productivity, tax revenues and a heavy social protection burden (Perry, 2007).

Workers may be informally employed because of low accessibility through several channels. First, faced with costly commutes, they may be discouraged to commute to formal jobs and opt for informal occupations near or at home (Moreno-Monroy and Posada, 2014). Furthermore, workers with low accessibility to jobs are spatially constrained, which limits their job search to their local environment (Phillips, 2014; Zenou, 2009), in which informal occupations may be disproportionally present especially in low income areas. In large metropolitan regions with long commutes formal employers may discriminate against workers based on place of residency because of the effects of long commutes on productivity (Gobillon et al., 2007). These effects are more likely to occur if jobs are strongly concentrated in the city center, if the wage gap between the formal and informal sectors does not compensate for higher commuting costs, if home-based labor is prevalent, and if areas where lower-income individuals reside have poor accessibility to jobs.

The aim of this paper is thus to empirically explore the relationship between job informality and accessibility to jobs by public transport in São Paulo Metropolitan Region (SPMR), Brazil. To do so, we first calculate a cumulative-opportunity measure of job accessibility for 633 Área Espacial de Ponderacão (AEP) areas within the SPMR. AEP is similar to census tract approach in a developed country census, yet it is a little bigger in size. It is designed to give the necessary statistical robustness to the Population Census sampling strategy. We then use a multilevel mixed-effects logistic regression model to estimate the effect of job accessibility by public transport on the likelihood of being informally employed, controlling for individual and other area characteristics. In order to account for informal sector heterogeneity, we split our sample in two groups based on whether a worker earns less or more than the minimum wage. The study discusses the current patterns in the provision of public transport and contributes to the research on accessibility in emerging and developing countries. The findings of this study can be of relevance to planners and transportation agencies wishing to better understand the relationship between public transport provision in countries with segmented labor markets and significant presence of informal employment.

The paper is structured in 5 sections. The first section presents an overview of the literature on informality and accessibility by public transport. The SPMR context is then presented, followed by a description of the data and methodology. Next, the spatial patterns of accessibility by transit and informality are presented. 
These results are followed by an econometric analysis of the likelihood of being informally employed as a function of the level of accessibility to jobs by public transport while controlling for individual and area characteristics. We conclude the paper with a discussion of the implications of our findings.

\section{Background}

Our work relates to a strand of literature studying the determinants of informality at the worker level (Gong and Van Soest, 2002; Marcouiller et al., 1997). This literature suggests that characteristics such as a lower educational attainment, being young, and having less years of experience are associated with a higher probability of working in the informal job sector (Angel-Urdinola and Tanabe, 2012). Previous research analyzing the determinants of informal employment have focused on a mixture of personal, regional, and institutional characteristics (Almeida and Carneiro, 2009; Jonasson, 2011), but have not explicitly modeled the effect of city and neighborhood characteristics on informality rates (Moreno-Monroy and Ramos, 2015).

On the other hand, there is a rich and growing literature focusing on the measurement, causes and consequences of job accessibility on employment outcomes mostly in developed countries, which has not yet explicitly addressed informal employment due to its small percentage in developed world. Blumenberg and Ong (2001) found that long and unreliable commuting times by public transport negatively impact the ability of low-income populations to find work. Similarly, Kawabata (2003) found that low-skilled workers are more likely to be employed, and to be employed full-time, if they have better accessibility to jobs by Public transport. Sanchez (1999) and Tyndall (2015) found that, more generally, access to public transport results in higher employment rates in North American context. In the European context, similar conclusions have been drawn (Matas et al., 2010; Sari, 2015). This shows that previous research in developed countries focused on unemployment rates and their relation to public transport or accessibility to jobs. Meanwhile, in emerging and developing countries the job market is divided into two categories, formal and informal. Informal job sector in countries like Brazil can reach up to $50 \%$ of the job market in some cities. Accordingly, it becomes relevant to study the effect of accessibility by public transport on informal employment. It is important to note that informal employment is an outside option to formal employment and cannot be directly equated to unemployment. Unlike developed countries, emerging and developing countries do not offer unemployment benefits, so many workers, especially those in the lower income categories cannot afford to be unemployed and have to find alternatives in the informal sector. Informality may be an attractive alternative for some workers seeking higher flexibility, more autonomy, and even shorter commutes. Accordingly informality may be seen as a matter of choice to some extent for some individuals, while for others it can be seen as the last resort to obtain a living wage (Günther and Launov, 2012; Maloney, 2004; Perry, 2007).

In the context of developing countries, informality of land tenure also plays an important role in the relationship between labor informality and job accessibility. Most large cities in emerging and developing economies host large informal settlements characterized by poor public infrastructure provision, difficult access to activity centers, and high incidence of informal employment. These areas emerge as a solution for the urban poor to reside in a low cost housing where regulations and taxation are generally not imposed. Yet government do not usually provide services to these areas on regular basis and they receive the lowest share of attention in many regions. 
The combination of a disadvantageous location with respect to economic opportunities and lack of local transport infrastructure means that lower income workers are more likely to be "transport disadvantaged", so that poor access to transport ultimately results in higher social exclusion (Hernandez and Titheridge, 2016). Along these lines, informal transport has appeared in some cities as an alternative to bridge the provision gap faced by the lower income population (Cervero and Golub, 2007). However, in more heavily regulated environments where informal transport networks disappear once they are integrated to the formal system, the transport options available to the lower income workers are in many cases limited to walking or cycling. Accordingly lower income workers are spatially constrained in term of jobs that they can access. A recent study analyzed the differential commuting patterns of formal and informal workers in Rio de Janeiro (Motte et al., 2016). The study found that informal workers commute with less frequency than formal workers and make shorter trips, and that this is related to the fact that informal jobs are more decentralized than formal jobs. Our study complements this literature stream by considering the relationship between job accessibility by transit and the probability of working in the informal job sector.

\section{Area of Study and Data}

\subsection{Area of Study}

The area of study is the São Paulo Metropolitan Region (SPMR), the largest Brazilian metropolis with about 19.5 million inhabitants where on average 30 percent of the labor force was informally employed in 2010. The SPMR is geographically divided by the Tietê and Tamanduatei Rivers, running from the NorthWest to the South-East of the region (see Figure 1). A subway system serves the center of the region, with a denser service west of the Tamanduatei River, around the expanded Central Business District (CBD), where higher-income and higher-job density areas are located. A rail system serves the region, characterized by a lower frequency and slower speed than the subway system. Dedicated bus lines also serve the region, implemented to compensate the lack of subway service. With respect to modal share in the region, there is a discrepancy in public transport use between low-income and high-income households. In 2007, $77 \%$ of the trips of low-income households were made using public transport modes, compared to $21 \%$ for highincome populations (Diretoria de planejamento e expansao dos transportes metropolitanos, 2008). This suggests a high public transport dependency among low-income households.

\subsection{Data on Travel Time, Jobs and Informality Status}

Our unit of analysis is the Área Espacial de Ponderacão (AEP). It is defined as an area composed by a mutually exclusive set of zones designed to give the necessary statistical robustness to the Population Census sampling strategy. The 2010 Census includes 633 AEPs, with an average population of 31,096 inhabitants, and an average area of $12.55 \mathrm{~km}^{2}$.

Travel times from each AEP to every other AEP are obtained through Google Maps Distance Matrix API (Google Maps, Accessed September 20, 2015), using the AEP geographic centroids. The fastest route requiring fewer transfers is returned by the application, based on the Google Maps algorithm and using the Google Transit Feed Specifications (GTFS). The departure time is set at 7 am to capture accessibility at peak hour, as the highest number of work-related trips depart between 7 am and 8 am in the SPMR (Diretoria de planejamento e expansao dos transportes metropolitanos, 2008). The waiting time at the beginning of the trip is not accounted for in the algorithm. By directly using the GTFS data, we could have accounted for the waiting time. Yet, the GTFS data for all the municipalities of the SPMR was not openly available. Although different departure times and algorithm specifications (i.e.: including waiting time) 
might yield slightly different travel times, the selected method is appropriate for this study, which aims at investigating the broad accessibility trends.

The number of jobs in each AEP is estimated from the 2007 Origin-Destination survey (Diretoria de planejamento e expansao dos transportes metropolitanos, 2008). The number of jobs in each AEP corresponds to the number of work trips ending in this AEP, multiplied by the expansion factor. By this measure, there were 9,111,952 jobs (formal and informal) in the SPMR.

The micro-data for the individual characteristics, including those related to being an informal worker, is obtained from the 2010 Population Census (Instituto Brasileiro de Geografia e Estatistica, 2010). In order to determine the status of each worker, we use variables on occupational status and type of employment (on the main job), and whether the person made contributions to social security. A worker is classified as informal if he or she is an unregistered employee (empregado sem carteira assinada), or a self-employed individual not contributing to social security, or an employer not contributing to social security (Henley et al., 2009; Jonasson, 2011). A formal worker, by contrast, is a registered employee (empregado com carteira assinada), or self-employed individual contributing to social security, or an employer contributing to social security. As explained by Jonasson (2011), who uses similar criteria, this definition corresponds to the "no signed labor card" criteria of Henley et al. (2009). From the census, it is possible to know where the AEP of residency, but there is no information available regarding the area of work. Finally, it is worth noting that the benefits of having a "signed work card" in Brazil include a minimum of 25 days of vacation, a maximum work week of 44 hours, an overtime premium, 13th month pay, four months of maternity leave, five days paternity leave, one month notice for firing, and a public transport stipend for work trips (a scheme called Vale Transporte).

\subsection{Data Limitations}

There are some limitations with the data used in this study. Firstly, the informality status is derived from the census data, and is accordingly dependent on people truthfully reporting their status. As some people might want to disguise that they are working informally, our data might be overestimating the number of formally employed individuals. However, given the relatively large sample size, the data allows exploring the relationship between informality and accessibility to jobs by transit. Secondly, due to restrictions on data availability, the location of jobs, the census data and the transit schedule used in this study are from different years. Lastly, accessibility is generated at the aggregated level, based on the geographic centroids of the AEP in which individuals reside. Accordingly, this might not fully reflect the level of accessibility of the home location of individuals. Nevertheless, this type of aggregated analysis allows exploring accessibility patterns at the regional level, as done in previous studies (Bocarejo and Oviedo, 2012; Foth et al., 2014; Tyndall, 2015).

\subsection{Descriptive statistics}

Figure 1 shows the spatial distribution of jobs (formal and informal) and average income. The SPMR displays a strong core-periphery division: jobs are highly concentrated in the west-central part of the region which also displays the highest average income (Diretoria de planejamento e expansao dos transportes metropolitanos, 2008). In contrast, low-income areas are mainly situated in peripheral regions where there are not many jobs. Additionally, the city displays a clear East-West divide, with low-income areas are situated on the east side, and high income areas with a particularly high concentration of employment 
opportunities on the west side of the Tamanduatei river. The spatial distribution of jobs (formal and informal) and low-income households, combined with high transit dependency, poses significant challenges for low-income populations to access employment opportunities in the SPMR.
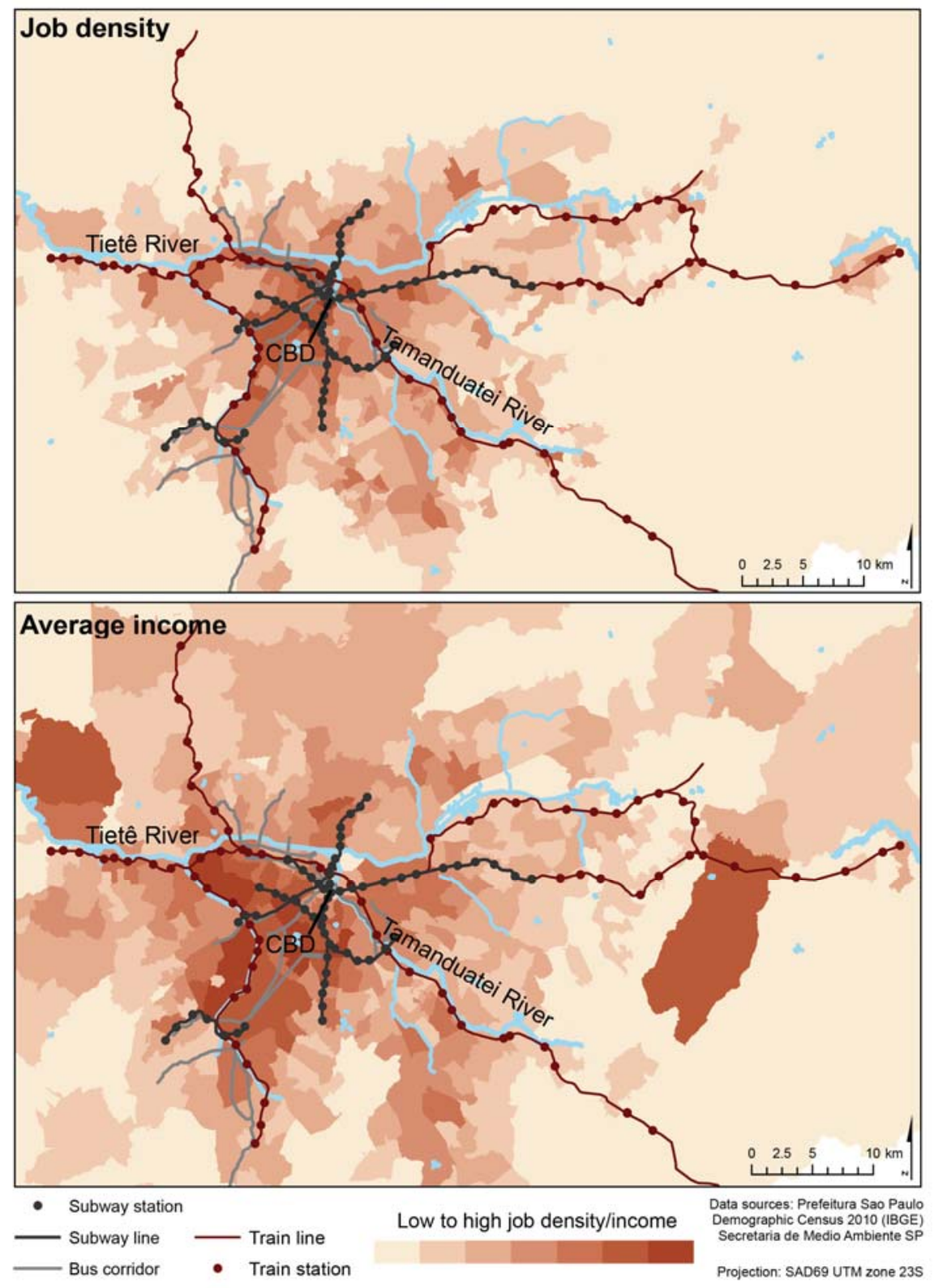

Figure 1: Job density and average income in the São Paulo Metropolitan Region

\section{Methods}

To explore the relationship between accessibility to jobs (formal and informal) by transit and informality, we first define our accessibility measure. The likelihood of a worker to be informally employed as a function 
of its level of accessibility to jobs by transit is then assessed using a multilevel mixed-effects logistic regression, controlling for individual characteristics and spatial effects.

\subsection{Accessibility measures}

Accessibility measures are generated at the AEP level, based on a cumulative-opportunity measure. Cumulative-opportunity measures are most commonly used in research, as they provide an easy-to-interpret measure of accessibility (Geurs and van Wee, 2004). Cumulative-opportunity measures are frequently used to measure the spatial distribution of accessibility, as done by Wang and Chen (2015). This type of measure counts the number of jobs that can be reached from one AEP using transit, under a specified travel time threshold, and is calculated as follows:

$A_{i}=\sum_{j=1}^{n} O_{j} f\left(C_{i j}\right)$

$f\left(C_{i j}\right)=\left\{\begin{array}{l}1 \text { if } C_{i j} \leq t \\ 0 \text { if } C_{i j}>t\end{array}\right.$

where $A_{i}$ is the accessibility at point $\mathrm{i}$ to all jobs in area (AEP) $\mathrm{j}, O_{j}$ the number of jobs in AEP $\mathrm{j}$ and $f\left(C_{i j}\right)$ the weighting function with $C_{i j}$ being the time cost of travel from i to $\mathrm{j}$ and $\mathrm{t}$, the travel time threshold. The jobs are counted if they are located within the travel time threshold. In this study, a travel time threshold of 60 minutes is used, where the average travel time by transit in the SPMR is 67 minutes (Diretoria de planejamento e expansao dos transportes metropolitanos, 2008).

\subsection{Statistical analysis}

To control for individual and area characteristics, we specify a multilevel mixed-effects logistic regression model at the individual level as:

Informal $_{i j}=\alpha+\boldsymbol{x}_{\boldsymbol{i j}}^{\prime} \boldsymbol{\beta}+\gamma A c c_{j}+\boldsymbol{\delta} \boldsymbol{C a r}_{j}+\varepsilon_{i j}$

Where Informal ${ }_{i j}$ is a binary variable equal to 1 if worker i residing in area $\mathrm{j}$ is classified as informal, $\boldsymbol{x}_{\boldsymbol{i} \boldsymbol{j}}$ is a matrix including individual-level (exogenous) characteristics related to informality, $A c c_{j}$ is accessibility to jobs by public transport in area $\mathrm{j}$ transformed using a natural logarithm function, and $\mathrm{Car}_{j}$ is a variable indicating car ownership rates in area $\mathrm{j}$. Unfortunately, there is no information available on car ownership at the individual level so we opt for using information on car ownership rates from the household census data at the area level to control for the presence of an alternative mode.

The individual characteristics include: age (and age-squared), gender, dummy variables for being the head of the household (defined as the person of the household with the highest income), having a low educational level (i.e. having attended school only up to the basic education level (Ensino Fundamental, equivalent to five years or primary school)), being married, being a migrant (i.e., not born in the SPMR), being disabled, and having at least one child below the age of 10 .

The mixed-effects logistic regression model predicts the likelihood of a worker to be informally employed. The regression analysis was restricted to respondents that are workers (formally or informally employed) 
between the age of 10 and 70 years-old inclusively, leading to a sample of 476,688 individuals ${ }^{1}$. The point estimate of $\gamma$ cannot be directly interpreted as the (causal) impact of job accessibility on informality, because the estimated coefficients may suffer from an omitted variables bias if there is another variable correlated with the likelihood of being informal and the covariates not included in the regression. To address this issue, alternative identification strategy could be pursed, for instance by finding an instrument for accessibility. This extended analysis lies beyond the scope of our paper. Given that our aim is to analyze the relationship between job accessibility and the likelihood of being informal, we refrain from interpreting the estimate of $\gamma$ as a measure of impact of job accessibility on informality throughout the article.

An important predictor of being informal that has not been included in the regression is income. This is a deliberate choice, because including the variable would result in biased estimates because of endogeneity: individuals could be informal because they have low incomes, but they could also have low incomes because they are informal. To address this issue, we split the sample into two categories based on the official minimum wage in Brazil in $2010^{2}$ (i.e., whether the worker nominal monthly income is less than the minimum wage or more) and ran the same regression model for each category.

Table 1 shows descriptive statistics for the variables included in the model. Low-income individuals have a lower average accessibility to jobs by public transport and reside in greater proportion in areas with lower car ownership. Also, the proportion of women is higher for low-income individuals, while the proportion of head of family and married individuals is lower.

Table 1: Summary statistics of the variables included in the regression model

\begin{tabular}{l|cccc|cccc}
\hline & \multicolumn{9}{|c|}{$\begin{array}{l}\text { Workers earning less than minimum } \\
\text { wage }(\mathrm{n}=42,468)\end{array}$} & \multicolumn{5}{c}{$\begin{array}{l}\text { Workers earning the minimum wage } \\
\text { or more }(\mathrm{n}=434,220)\end{array}$} \\
\hline \multicolumn{1}{c}{ Variable } & Mean & S.D. & Min & Max & Mean & S.D. & Min & Max \\
\hline $\begin{array}{l}\text { Job Accessibility } \\
\text { Car ownership } \\
(\%)\end{array}$ & 275,991 & 489,866 & 1 & $3,494,125$ & 478,875 & 738,038 & 1 & $3,494,125$ \\
Informality & 0.46 & 0.11 & 0 & 1 & 0.51 & 0.14 & 0.16 & 0.94 \\
Age & 0.72 & 0.45 & 0 & 1 & 0.24 & 0.43 & 0.00 & 1.00 \\
Gender (female $=$ & 38 & 13 & 10 & 70 & 37.814 & 11.928 & 10 & 70 \\
1) & & & & & & & & \\
Low education & 0.66 & 0.47 & 0 & 1 & 0.42 & 0.49 & 0.00 & 1.00 \\
Head of household & 0.38 & 0.49 & 0 & 1 & 0.46 & 0.50 & 0.00 & 1.00 \\
Married & 0.33 & 0.47 & 0 & 1 & 0.17 & 0.38 & 0.00 & 1.00 \\
Migrant & 0.38 & 0.49 & 0 & 1 & 0.46 & 0.50 & 0.00 & 1.00 \\
Disability & 0.60 & 0.49 & 0 & 1 & 0.52 & 0.50 & 0.00 & 1.00 \\
Children & 0.01 & 0.10 & 0 & 1 & 0.00 & 0.06 & 0.00 & 1.00 \\
& 0.24 & 0.43 & 0 & 1 & 0.13 & 0.34 & 0.00 & 1.00 \\
\hline
\end{tabular}

\footnotetext{
${ }^{1}$ Workers with zero income were excluded because in the 2010 Population Census, zeros could also refer to missing information. We also exclude workers who where also attending school in order to be able to use the variable "last course attended" to define our proxy for educational level.

${ }^{2}$ The official minimum wage in 2010 was set to $\mathrm{R} \$ 510,00$ per month by the Decree $\mathrm{N}^{\mathrm{o}} 12.255$ of June 15 , 2010.
} 


\section{Results}

\subsection{Accessibility and informality by areas}

Figure 2 shows the informality rate of each AEP in 2010 (lower section of the figure), defined as the sum of informal workers over the sum of formal and informal workers in each area. Informality rates are generally lower in the CBD and in the urban region south-west of the CBD. There also seems to be generally lower informality rates along the subway lines, where accessibility to jobs by transit is higher. In contrast, informality rates appear to be higher north-east of the CBD and in peripheral areas. While the second section of Figure 2 (upper section of the figure) shows accessibility to jobs by public transport.
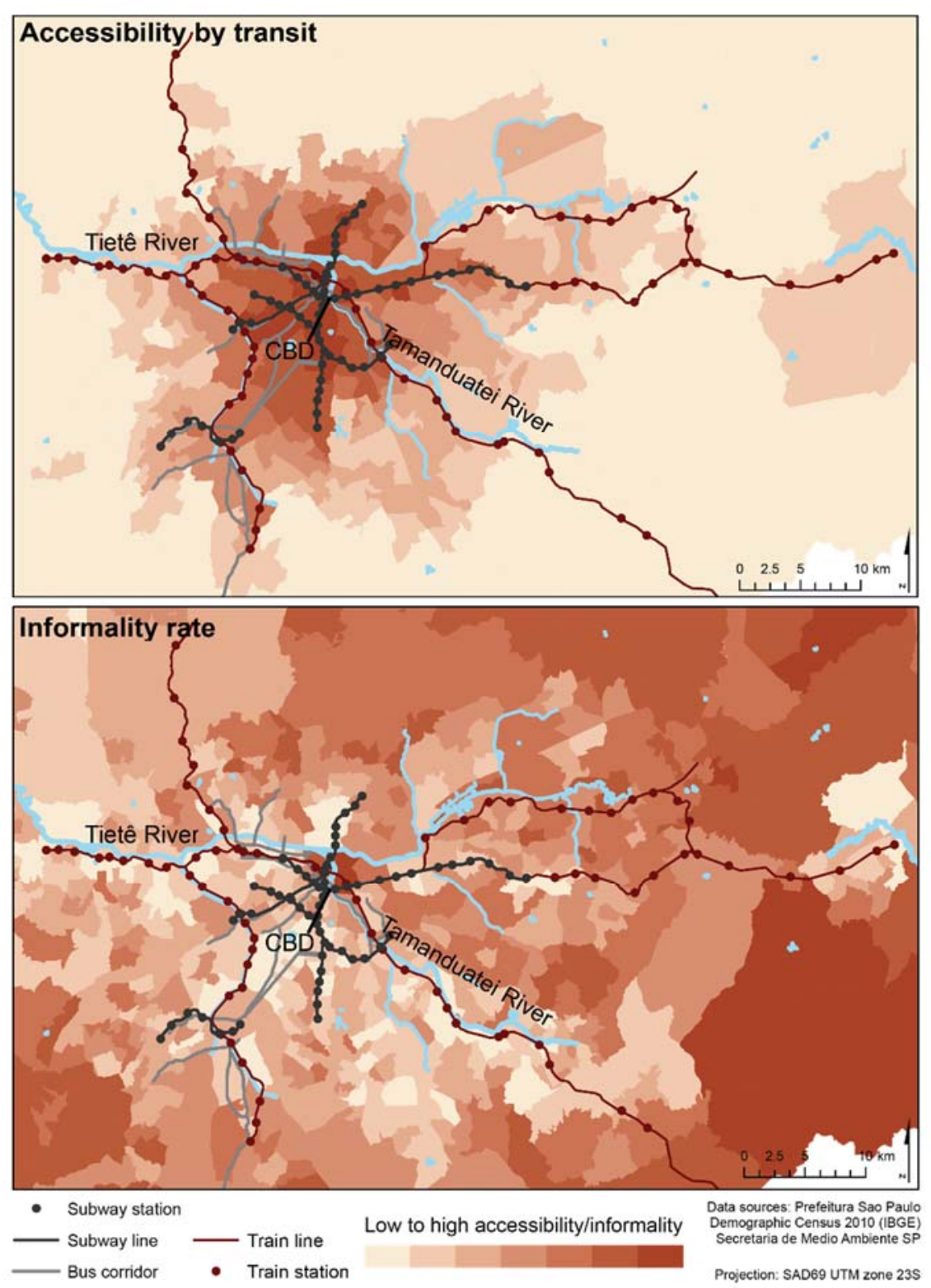

Figure 2: Accessibility to jobs by public transport and informality in SPMR 
The accessibility pattern combines the core-periphery structure and the influence of the subway lines. High levels of accessibility by public transport to jobs are found in the center and then decrease as the distance to the CBD increase. Regions at the periphery of the urban zone experience relatively low levels of accessibility by public transport to jobs, whereas regions outside the urban zone have the lowest levels of accessibility to jobs by public transport. Additionally, accessibility is generally higher along the subway lines. This general pattern suggests that residents that are centrally located have access to a greater number of jobs by public transport than the ones situated in the periphery. The same goes for residents located in proximity of a subway line.

Observing the two sections of the figure the spatial distribution of the informality rate seems to be correlated with the spatial pattern of accessibility to jobs by public transport, where AEP experiencing low levels of accessibility appear to be characterized by higher informality rates. This is supported by a correlation factor of -0.38 (natural logarithms). In other words, areas with high levels of accessibility to jobs by public transport generally have lower rates of informality. In Figure 3, the 2010 informality rate of each AEP is plotted as a function of accessibility to jobs by public transport. This figure confirms that areas with lower levels of accessibility to jobs by public transport tend to have higher informality rates.

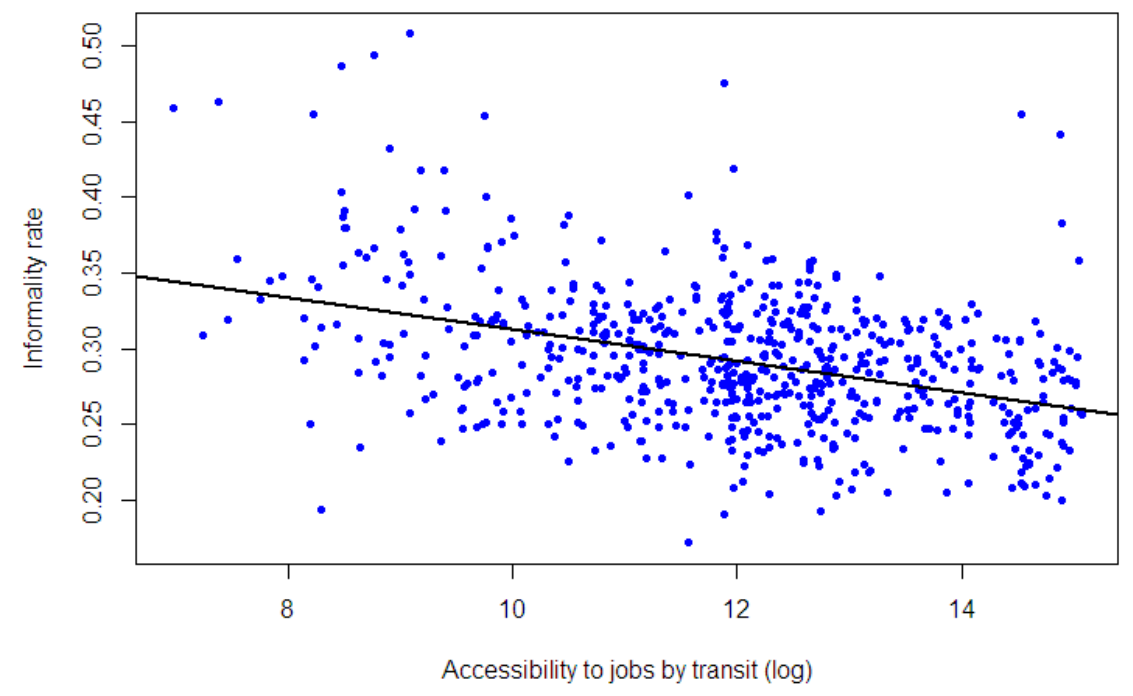

Figure 3: Informality rate and accessibility to jobs by transit for the SPMR, at the census tract level

In order to better understand the association between accessibility and informality at the individual level, the next section presents the multilevel mixed-effects regression model that controls for individual and area characteristics.

\subsection{Regression analysis results}

The results of the regression models are presented in Table 2. We compared running a multilevel model against regular logit and found that the likelihood-ratio test is statistically significant ( $\operatorname{Prob}>\mathrm{chi}^{2}=0.0000$ ), 
which means the data is clustered in the AEP and can lead to a bias in the estimation if not controlled for. The variance component of the random effects for each model are reported at the end of the table.

With respect to our variable of interest, the results show that accessibility by public transport to jobs is a statistically significant predictor of informality for workers earning below minimum wage. For these workers, the likelihood of being informally employed increases as the level of accessibility to jobs decreases. The odds ratio for this variable is 0.97 (exp -0.031), which means for every one percent increase in the accessibility to jobs by public transport in the area the possibility of an individual residing in this are being in an informal job decrease by $3 \%$ while keeping all other variables constant at their mean. Car ownership at the AEP level is not significantly correlated with the likelihood of being informally employed. A regression was also conducted without including the car ownership and the results are consistent, in terms of magnitude and significance for all variables. In sum, the results suggest that, for workers earning below minimum wage that residing in areas where job accessibility by public transport is lower is associated with a higher probability of being informally employed.

This relationship however does not hold when we consider workers earning above minimum wage. In this case, accessibility to jobs by public transport did not show a statistical significance effect on informality. In other words, for workers earning above minimum wage, the likelihood to be informally employed is not associated with the level of accessibility to jobs by public transport. On the other hand, a higher car ownership rate in the area of resident is associated with a lower likelihood of being informally employed.

The discrepancy in the statistical significance of accessibility to jobs by public transport is likely due to the fact that low-income workers are more reliant on public transport for their commuting. In contrast, workers earning above minimum wage are more likely to have other transportation options, namely through access to a car, which makes them less dependent on public transport. As a result, accessibility by public transport to jobs is not a significant predictor of informality for the higher income workers.

Age was found to react different between the two models. For the workers earning less than minimum wage age had a statically significant positive impact on the odds of being in the informal sector. This variable was tested with a square term to capture non-linear relation and was found not to be significant showing the relation is more linear for this group. While for the workers earning minimum wage and above this relation was found to be nonlinear (age and age square are both statistically significant in the model), in other words the odds of being in the informal job sector declines till a certain point and then increase again after a certain age. This is consistent with previous studies, suggesting that informality rates decrease with age (Gong and Van Soest, 2002; Jonasson, 2011). Regarding other individual control variables we found that being a migrant, having a low education level and having a child are positively and significantly associated with the likelihood of being informal for both samples. Disability appears to be positive and significant only for workers earning less than the minimum wage, while age is not significantly associated with the likelihood of working informally for this sample. Looking first at workers earning above minimum wage, apart from disability and being head of household, all variables are statistically significant at the $99 \%$ confidence level and are coherent with the literature. Being a female is negatively associated with the likelihood of working informally, although not significantly at the $95 \%$ level of confidence for the sample of workers below minimum wage. 
Table 2: Mixed-effects logistic regression results

\begin{tabular}{|c|c|c|c|c|}
\hline & \multicolumn{2}{|c|}{$\begin{array}{c}\text { Workers earning less than minimum } \\
\text { wage }\end{array}$} & \multicolumn{2}{|c|}{$\begin{array}{c}\text { Workers earning minimum wage or } \\
\text { more }\end{array}$} \\
\hline & Parameter & $95 \%$ Confidence interval & Parameter & 95\% Confidence interval \\
\hline Accessibility to jobs (In) & $-0.031 * *$ & $(-0.051--0.012)$ & 0.003 & $(-0.006-0.012)$ \\
\hline Car ownership & 0.151 & $(-0.136-0.438)$ & $-0.312 * *$ & $(-0.436--0.187)$ \\
\hline Age & $0.018 * *$ & $(0.015-0.020)$ & $-0.029 * *$ & $(-0.032--0.025)$ \\
\hline Age squared & & & $0.001 * *$ & $(0.001-0.0006)$ \\
\hline Gender (Female) & $-0.053^{*}$ & $(-0.103--0.002)$ & $-0.126^{* *}$ & $(-0.143--0.109)$ \\
\hline Head of household & 0.031 & $(-0.017-0.079)$ & 0.009 & $(-0.005-0.024)$ \\
\hline Low Education & $0.216^{* *}$ & $(0.165-0.267)$ & $0.437 * *$ & $(0.418-0.455)$ \\
\hline Married & $-0.093 * *$ & $(-0.141--0.045)$ & $-0.248^{* *}$ & $(-0.263--0.232)$ \\
\hline Migrant & $0.082 * *$ & $(0.035-0.130)$ & $0.114 * *$ & $(0.099-0.130)$ \\
\hline Disability & $0.284^{*}$ & $(0.045-0.522)$ & 0.009 & $(-0.106-0.125)$ \\
\hline Children & $0.375^{* *}$ & $(0.316-0.434)$ & $0.235^{* *}$ & $(0.210-0.259)$ \\
\hline \multirow[t]{2}{*}{ Constant } & $0.432^{* *}$ & $(0.194-0.669)$ & $-0.898 * *$ & $(-1.023--0.772)$ \\
\hline & Estimate & $95 \%$ Confidence interval & Estimate & $95 \%$ Confidence interval \\
\hline Multilevel var. comp. & 0.292 & $(0.261-0.327)$ & 0.174 & $(0.162-0.187)$ \\
\hline Log-likelihood & & $-24,563$ & & $-233,092$ \\
\hline Observations & & 42,468 & & 434,220 \\
\hline Number of groups & & 633 & & 633 \\
\hline
\end{tabular}

Overall, the results suggest that low-income workers residing in areas where job accessibility by public transport are lower and more likely to be informally employed. Several studies in the North American and European context have shown that the lack of accessibility to jobs by public transport is associated with higher unemployment rates (Matas et al., 2010; Sanchez, 1999; Sari, 2015; Tyndall, 2015). This study is to our knowledge the first to investigate the relationship between accessibility to jobs by public transport and informality, rather than unemployment. Taking into account the contextual differences, our results appear to be consistent with the previous findings on transit and unemployment. More specifically, in Brazil informality is explained by the low rate of finding jobs in the formal sector (Bosch et al., 2007). Against such background, the lack of accessibility by public transport to the job market can result in workers opting for an informal job, for which spatial constraints are smaller (Suárez et al., 2015). While it is not possible to draw conclusions on the causal relationship between accessibility and informal employment from our analysis, previous studies suggest that lack of accessibility to jobs by transit can play a role in informal employment. Our study demonstrates a clear association between informality and accessibility for lowincome workers in the SPMR, and thus highlights the need for future research to uncover the socio-spatial mechanisms associated with informal employment. 


\section{Conclusion}

This paper contributes to quantifying the relationship between informality and accessibility to jobs by public transport in the context of a developing country. The results show that accessibility to jobs by public transport is unevenly distributed across the region, largely concentrated in the core of the region while periphery areas exhibit relatively low levels of accessibility to jobs by public transport, where informality rates and low income groups are concentrated in the region.

The likelihood of being formally employed is positively correlated with the level of accessibility to jobs by public transport for low-income workers. For every one percent increase in the level of accessibility by public transport to jobs the probability of being in the informal job sector decrease by $3 \%$ while keeping all other variables constant at their mean. These results add to the literature on accessibility by public transport and employment. Whereas previous studies have found that the lack of job accessibility to jobs by public transport leads to higher unemployment rates in developed countries (Blumenberg and Ong, 2001; Kawabata, 2003; Matas et al., 2010; Sari, 2015), this study suggests that such low levels of accessibility to jobs by public transport could be associated with informal employment in the SPMR among low income individuals. In developing countries unemployment compensations are rare, so individuals are left with little choice except to be employed in the informal market to earn a living, especially for low-income groups. This relationship did not hold among higher income levels, who are more likely to have access to a car.

The findings from this study can be of value to engineers and planners as well as international development organizations directing public transport funds in developing countries with the aim of initiating economic development in the formal job sector to avoid many of the losses and discriminations associated to job informality. This research suggests that reducing informality rates among low-income workers in cities in the developing world could be partially achieved through expanding public transport services to areas with high informality rates and high proportions of low-income workers to help residents in these areas in reaching job opportunities as their low car ownership and absence of public transport can direct them more to informality. Additionally, supporting the decentralization of formal jobs could increase jobs accessibility in peripheral areas, where poverty and informality rates are higher. While individual factors are major contributors of informality, an equitable land use and transportation systems could provide broad support for reducing informality. The research therefore supports the need for further studies on informal employment and public transport, to better understand the potential impacts of land use and transportation interventions in developing countries.

\section{Acknowledgments}

We would like to thank Guillaume Barreau for modeling the transit trips and providing the travel time matrix used in the accessibility measures. Boisjoly and El-Geneidy gratefully acknowledge the financial support received from the Natural Sciences and Engineering Research Council of Canada (NSERC) and the Fonds de recherche du Québec-Nature et technologies (FRQNT). Moreno-Monroy gratefully acknowledges financial support from a Marie Curie Intra European Fellowship (PEIF-GA-2013-627114) within the 7th European Community Framework Programme. 


\section{List of references}

Almeida, R., Carneiro, P., 2009. Enforcement of labor regulation and firm size. Journal of comparative Economics 37, 28-46.

Angel-Urdinola, D., Tanabe, K., 2012. Micro-determinants of informal employemnt in the Middle East and North Africa region. World Bank.

Blumenberg, E., Ong, P., 2001. Cars, buses, and jobs-welfare participants and employment access in Los Angeles, Sustainability and environmental concerns in transportation 2001: Planning and administration; energy and environment, pp. 22-31.

Bocarejo, J., Oviedo, D., 2012. Transport accessibility and social inequities: A tool for identification of mobility needs and evaluation of transport investments. Journal of Transport Geography 24, 142-154. Bosch, M., Goni, E., Maloney, W.F., 2007. The determinants of rising informality in Brazil: Evidence from gross worker flows. World Bank Policy Research Working Paper Series, Vol.

Camara, P., Banister, D., 1993. Spatial inequalities in the provision of public transport in Latin-American cities. Transport Reviews 13, 351-373.

Cervero, R., Golub, A., 2007. Informal transport: A global perspective. Transport policy 14, 445-457. Diretoria de planejamento e expansao dos transportes metropolitanos, 2008. Pesquisa Origem e Destino 2007. http://www.stm.sp.gov.br/, Sao Paulo.

Foth, N., Manaugh, K., El-Geneidy, A., 2014. Determinants of Mode Share over Time How Changing Transport System Affects Transit Use in Toronto, Ontario, Canada. Transportation Research Record, 6777.

Geurs, K., van Wee, B., 2004. Accessibility evaluation of land-use and transport strategies: review and research directions. Journal of Transport Geography 12, 127-140.

Gobillon, L., Selod, H., Zenou, Y., 2007. The mechanisms of spatial mismatch. Urban studies 44, 24012427.

Gong, X., Van Soest, A., 2002. Wage differentials and mobility in the urban labour market: A panel data analysis for Mexico. Labour Economics 9, 513-529.

Google Maps, Accessed September 20, 2015.

https://developers.google.com/maps/documentation/distance-matrix/intro.

Günther, I., Launov, A., 2012. Informal employment in developing countries: Opportunity or last resort? Journal of development economics 97, 88-98.

Henley, A., Arabsheibani, G., Carneiro, F., 2009. On defining and measuring the informal sector: Evidence from Brazil. World development 37, 992-1003.

Hernandez, D., Titheridge, H., 2016. Mobilities of the periphery: Informality, access and social exclusion in the urban fringe in Colombia. Journal of Transport Geography 55, 152-164.

Instituto Brasileiro de Geografia e Estatistica, 2010. Demographic census 2010.

Jonasson, E., 2011. Informal employment and the role of regional governance. Review of Development Economics 15, 429-441.

Kawabata, M., 2003. Job access and employment among low-skilled autoless workers in US metropolitan areas. Environment and Planning A 35, 1651-1668.

Maloney, W., 2004. Informality revisited. World development 32, 1159-1178.

Marcouiller, D., de Castilla, V., Woodruff, C., 1997. Formal measures of the informal-sector wage gap in Mexico, El Salvador, and Peru. Economic development and cultural change 45, 367-392.

Matas, A., Raymond, J., Roig, J., 2010. Job accessibility and female employment probability: The cases of Barcelona and Madrid. Urban Studies.

Moreno-Monroy, A., Posada, H., 2014. On the effect of transport subsidies on informality rates. CEPESP discussion paper, Fundação Getulio Vargas. 
Moreno-Monroy, A., Ramos, F., 2015. The impact of public transport expansions on informality: The case of the São Paulo Metropolitan Region.

Motte, B., Aguilera, A., Bonin, O., Nassi, C.D., 2016. Commuting patterns in the metropolitan region of Rio de Janeiro. What differences between formal and informal jobs? Journal of Transport Geography 51, 59-69.

Perry, G., 2007. Informality: Exit and exclusion. World Bank Publications.

Phillips, D., 2014. Getting to work: Experimental evidence on job search and transportation costs. Labour Economics 29, 72-82.

Sanchez, T.W., 1999. The connection between public transit and employment: the cases of Portland and Atlanta. Journal of the American Planning Association 65, 284-296.

Sari, F., 2015. Public transit and labor market outcomes: Analysis of the connections in the French agglomeration of Bordeaux. Transportation Research Part A: Policy and Practice 78, 231-251.

Suárez, M., Murata, M., Campos, J., 2015. Why do the poor travel less? Urban structure, commuting and economic informality in Mexico City. Urban Studies, 0042098015596925.

Tyndall, J., 2015. Waiting for the R train: Public transportation and employment. Urban Studies, 0042098015594079.

Wang, C., Chen, N., 2015. A GIS-based spatial statistical approach to modeling job accessibility by transportation mode: Case study of Columbus, Ohio. Journal of Transport Geography 45, 1-11.

Zenou, Y., 2009. Urban labor economics. Cambridge University Press. 